\title{
On the stability of Jensen functional equation in Felbin's type fuzzy normed
}

\author{
linear spaces \\ Wenping Xue ${ }^{1, a}$, Peisheng $\mathrm{Ji}^{2, b}$ \\ ${ }^{1,2}$ College of Mathematics,Qing Dao University,Qing Dao 266071,P.R.China \\ a1107597917@qq.com, ${ }^{b}$ jipeish@yahoo.com
}

Keywords: stability; Felbin's type fuzzy normed linear spaces; Jensen functional equation.

Abstract.In this paper,we investigate the generalized Hyers-Ulam-Rassias stability of Jensen functional equation in Felbin's type fuzzy normed linear spaces .

\section{Introduction}

In 1940, Ulam[1] proposed the general Ulam stability problem.Next year, Hyers[2] solved this problem.In 1978, Rassias[3] took account of the unbounded Cauchy difference in Hyers' theorem and obtained the results for linear mappings. The stability problems of several functional equations have been extensively investigated by a number of authors (see [4,5] and references therein).In 1989,Kominek[6] proved the stability of Jensen functional equation on a restricted domain.In1998, Jung[7] proved the Hyers-Ulam-Rassias stability of Jensen functional equation. In 2014, Eskandani and Rassias[8] investigated the stability of a general cubic functional equation in Felbin's type fuzzy normed linear spaces. In this paper,we investigate the generalized Hyers-Ulam-Rassias stability of Jensen functional equation in Felbin's type fuzzy normed linear spaces .

We consider some basic concepts concerning in the theory of fuzzy real numbers. Let $\beta$ be a fuzzy subset on $\mathrm{R}$, i.e., a mapping $\beta: \mathrm{R} \rightarrow[0,1]$ associating with each real number $t$ its grade of membership $\beta(t)$.

Definition1.1 ${ }^{[9]} \mathrm{A}$ fuzzy subset $\beta$ on $\mathrm{R}$ is called a fuzzy real number,whose $\alpha$-level set is denoted by $[\beta]_{\kappa}$, i.e., $[\beta]_{\alpha}=\{\mathrm{t:} \beta(\mathrm{t}) \geq \alpha\}$,if it satisfies two axioms:

(1)There exists $t_{0} \in R$ such that $\beta\left(t_{0}\right)=1$.

(2)For each $\alpha \in(0,1]$; $[\beta]_{\alpha}=\left[\beta_{\alpha}^{-}, \beta_{\alpha}^{+}\right]$where $-\infty<\beta_{\alpha}^{-} \leq \beta_{\alpha}^{+}<+\infty$.

The set of all fuzzy real numbers denoted by $F(R)$.If $\beta \in F(R)$ and $\beta(t)=0$ whenever $\mathrm{t}<0$, then $\beta$ is called a nonnegative fuzzy real number and $\mathrm{F}^{*}(\mathrm{R})$ denotes the set of all non-negative fuzzy real numbers.

Definition1.2 ${ }^{[9]}$ Let $\mathrm{X}$ be a real linear space, L and R (respectively, left norm and right norm) be 
symmetric and non-decreasing mappings in both arguments from $[0,1] \times[0,1]$ into $[0,1]$ satisfying $\mathrm{L}(0,0)=0$ and $\mathrm{R}(1,1)=1$. The mapping $\|\cdot\|$ from $X$ into $\mathrm{F}^{*}(\mathrm{R})$ is called a fuzzy norm if for $\mathrm{x} \in \mathrm{X}$ and $\alpha \in(0,1]$ :

(1) $\|x\|=\overline{0}$ if and only if $x=0$,

(2) $\|\mathrm{rx}\|=|\mathrm{r}|\|\mathrm{x}\|$ for all $\mathrm{x} \in \mathrm{X}$ andr $\in(-\infty,+\infty)$;

(3)For all $\mathrm{x}, \mathrm{y} \in \mathrm{X}$,

(a) if $\mathbf{s} \leq\|\mathrm{x}\|_{1}^{-}, \mathrm{t} \leq\|\mathrm{y}\|_{1}^{-}$and $\mathrm{s}+\mathrm{t} \leq\|\mathrm{x}+\mathrm{y}\|_{1}^{-}$then $\|x+y\|(s+t) \geq L(\|x\|(s),\|y\|(t))$,

(b)if $\mathbf{s} \leq\|\mathrm{x}\|_{1}^{-}, \mathrm{t} \leq\|\mathrm{y}\|_{1}^{-}$and $\mathbf{s}+\mathrm{t} \geq\|\mathrm{x}+\mathrm{y}\|_{1}^{-}$then $\|x+y\|(s+t) \leq R(\|x\|(s),\|y\|(t))$.

The quaternary $(\mathrm{X},\|\cdot\|, \mathrm{L}, \mathrm{R})$ is called a fuzzy normed linear space.

Definition1.3 ${ }^{[9]}$ Let $(X,\|\|, L, R$.$) be a fuzzy normed linear space and \lim _{a \rightarrow 0^{+}} R(a, a)=0$. A sequence $\left\{x_{n}\right\}$ in $X$ is said to converge to $x \in X$, denoted by $\lim _{n \rightarrow \infty} x_{n}=x$, if $\lim _{n \rightarrow \infty}\left\|x_{n}-x\right\|_{\alpha}^{+}=0$ for every $\alpha \in(0,1]$ and is called a Cauchy sequence if $\lim _{n, m \rightarrow \infty}\left\|x_{n}-x_{m}\right\|_{\alpha}^{+}=0$ for every $\alpha \in(0,1]$.A subset $A$ in $X$ is said to be complete if every Cauchy sequence in A converges in A.The fuzzy normed space (X,\|. $\|, L, R)$ is said to be a fuzzy Banach space if it is complete.

Theorem1.4 ${ }^{[10]}$ Let $(X,\|\|, L, R$.$) be a fuzzy normed linear space, if \mathrm{R}(\mathrm{a}, \mathrm{b}) \leq \max (\mathrm{a}, \mathrm{b})$, then for any $\alpha \in(0,1],\|x+y\|_{\alpha}^{+} \leq\|x\|_{\alpha}^{+}+\|y\|_{\alpha}^{+}$for all $x, y \in X$.

A mapping $\mathrm{f}: \mathrm{X} \rightarrow \mathrm{Y}$ is called a Jensen function if $\mathrm{f}$ satisfies the functional equation

$$
2 f\left(\frac{x+y}{2}\right)=f(x)+f(y)
$$

for $\mathrm{x}, \mathrm{y} \in \mathrm{X}$.For a given mapping $\mathrm{f}: \mathrm{X} \rightarrow \mathrm{Y}$, we define the difference operator

$$
D f(x, y)=f(x)+f(y)-2 f\left(\frac{x+y}{2}\right)
$$

for $\mathrm{x}, \mathrm{y} \in \mathrm{X}$.Then $\mathrm{f}$ is a Jensen function if $\mathrm{Df}(\mathrm{x}, \mathrm{y})=0$ for all $\mathrm{x}, \mathrm{y} \in \mathrm{X}$. 


\section{Stability of Jensen functional equation using direct method.}

Theorem2.1 Let $\mathrm{X}$ be a real liner space and $(\mathrm{Y},\|\|,. \mathrm{L}, \mathrm{R})$ be a fuzzy Banach space satisfying $\mathrm{R}(\mathrm{a}, \mathrm{b}) \leq \max (\mathrm{a}, \mathrm{b})$.Let $\mathrm{f}: \mathrm{X} \rightarrow \mathrm{Y}$ be $\mathrm{a}$ mapping for which there exists a function $\varphi: \mathrm{X} \times \mathrm{X} \rightarrow \mathrm{F}^{*}(\mathrm{R})$ such that

$$
\begin{gathered}
\lim _{\mathrm{n} \rightarrow \infty} \frac{1}{2^{\mathrm{n}}} \varphi\left(2^{\mathrm{n}} \mathrm{x}, 2^{\mathrm{n}} \mathrm{y}\right)_{\alpha}^{+}=0, \\
\widetilde{\varphi}_{\alpha}(\mathrm{x})=\sum_{\mathrm{i}=0}^{\infty} \frac{1}{2^{\mathrm{i}+1}} \varphi\left(0,2^{\mathrm{i}+1} \mathrm{x}\right)_{\alpha}^{+}<\infty, \\
\|\mathrm{Df}(\mathrm{x}, \mathrm{y})\|_{\alpha}^{+} \leq \varphi(\mathrm{x}, \mathrm{y})_{\alpha}^{+}
\end{gathered}
$$

for all $\mathrm{x}, \mathrm{y} \in \mathrm{X}, \alpha \in(0,1]$. Then there exists a Jensen function $\mathrm{J}: \mathrm{X} \rightarrow \mathrm{Y}$ such that

$$
\|\mathrm{f}(\mathrm{x})-\mathrm{J}(\mathrm{x})\|_{\alpha}^{+} \leq \widetilde{\varphi}_{\alpha}(\mathrm{x})
$$

for all $\mathrm{x} \in \mathrm{X}, \alpha \in(0,1]$.

Proof. Define $g: X \rightarrow Y$ by $g(x)=f(x)-f(0)$ for all $x \in X$. Letting $x=0$ in (2.3), we get

$$
\begin{aligned}
& \left\|f(0)+f(y)-2 f\left(\frac{y}{2}\right)\right\|_{\alpha}^{+}=\left\|f(y)-f(0)-2\left(f\left(\frac{y}{2}\right)-f(0)\right)\right\|_{\alpha}^{+} \\
& =\left\|g(y)-2 g\left(\frac{y}{2}\right)\right\|_{\alpha}^{+} \leq \varphi(0, y)_{\alpha}^{+}
\end{aligned}
$$

for all $y \in X, \alpha \in(0,1]$. Replacing y by $2^{\mathrm{n}+1} \mathrm{x}$ in $(2.5)$ and dividing both sides by $2^{\mathrm{n}+1}$, we get

$$
\left\|\frac{1}{2^{n+1}} g\left(2^{n+1} x\right)-\frac{1}{2^{n}} g\left(2^{n} x\right)\right\|_{\alpha}^{+} \leq \frac{1}{2^{n+1}} \varphi\left(0,2^{n+1} x\right)_{\alpha^{*}}^{+}
$$

By theorem1.4 and inequality (2.6), we get

$$
\left\|\frac{1}{2^{\mathrm{n}+1}} \mathrm{~g}\left(2^{\mathrm{n}+1} \mathrm{x}\right)-\frac{1}{2^{\mathrm{m}}} \mathrm{g}\left(2^{\mathrm{m}} \mathrm{x}\right)\right\|_{\alpha}^{+} \leq \sum_{\mathrm{i}=\mathrm{m}}^{\mathrm{n}} \frac{1}{2^{\mathrm{i}+1}} \varphi\left(0,2^{\mathrm{i}+1} \mathrm{x}\right)_{\alpha}^{+}
$$

for all $\mathrm{x} \in \mathrm{X}, \alpha \in(0,1]$ and all non-negative integers $\mathrm{m}$ and $\mathrm{n}$ with $\mathrm{n} \geq \mathrm{m}$. Passing the limit $\mathrm{m}, \mathrm{n} \rightarrow \infty$ in (2.7), we have

$$
\lim _{m, n \rightarrow \infty}\left\|\frac{1}{2^{n+1}} g\left(2^{n+1} x\right)-\frac{1}{2^{m}} g\left(2^{m} x\right)\right\|_{\alpha}^{+}=0 .
$$


Therefore the sequence $\left\{\frac{1}{2^{n}} g\left(2^{n} x\right)\right\}$ is a Cauchy sequence in $Y$ for all $x \in X$.Since $Y$ is complete, the sequence $\left\{\frac{1}{2^{n}} g\left(2^{n} x\right)\right\}$ converges for all $x \in X$. So we can define the mapping $A: X \rightarrow Y$ by $A(x)=\lim _{n \rightarrow \infty} \frac{1}{2^{n}} g\left(2^{n} x\right)$

If we define a function $\mathrm{J}: \mathrm{X} \rightarrow \mathrm{Y}$ by $\mathrm{J}(\mathrm{x})=\mathrm{A}(\mathrm{x})+\mathrm{f}(0)_{\mathrm{s}}$ and let $\mathrm{m}=0$ and $\mathrm{n} \rightarrow \infty$ in (2.7), then $\|J(x)-f(x)\|_{\alpha}^{+}=\|A(x)-f(x)+f(0)\|_{\alpha}^{+}=\|A(x)-g(x)\|_{\alpha}^{+} \leq \widetilde{\varphi}_{\alpha}(x)$.We get (2.4). Now, we show that $\mathrm{J}$ is a Jensen function.

$$
\begin{aligned}
& \|\mathrm{DJ}(\mathrm{x}, \mathrm{y})\|_{\alpha}^{+}=\|\mathrm{D}(\mathrm{A}(\mathrm{x}, \mathrm{y})+\mathrm{f}(0))\|_{\alpha}^{+}=\left\|\lim _{\mathrm{n} \rightarrow \infty} \frac{1}{2^{\mathrm{n}}} \mathrm{Df}\left(2^{\mathrm{n}} \mathrm{x}, 2^{\mathrm{n}} \mathrm{y}\right)\right\|_{\alpha}^{+} \\
& \leq \lim _{\mathrm{n} \rightarrow \infty} \frac{1}{2^{\mathrm{n}}} \varphi\left(2^{\mathrm{n}} \mathrm{x}, 2^{\mathrm{n}} \mathrm{y}\right)_{\alpha}^{+}=0 .
\end{aligned}
$$

So $\mathrm{J}$ is a Jensen function.

\section{References}

[1]S.M.Ulam,A collection of mathematical problems[J],Interscience,NewYork,(1960).

[2]D.H.Hyers, On the stability of the linear functional equation[J], Proc. Nat. Acad. Sci. U.S.A.27, 222-224(1941). MR 2,315a. Zbl 061.26403.

[3]Th.M.Rassias,On the stability of the linear mapping in Banach spaces[J],Proc.Am. Math.Soc.72,297-300(1978).

[4]Soon-Mo Jung, Hyers-Ulam-Rassias stability of functional equations in nonlinear analysis[M],Spring Optimization and Its Applications 48.

[5]C.Hark,J.R.Lee,Approximation of an AQCQ-functional equation and its applications[J], Austro J.Math,Anal.Appl.,8(1):1-34,2011.(Art.14).

[6]Z.Kominek, On a local stability of the Jensen function equation[J],Demonstratio Math.22,499-507(1989).

[7]S.M.Jung,Hyers-Ulam-Rassias stability of Jensen's equation and its application[J],Proc.Amer.Math.Soc.126,3137-3143(1998).

[8]G.Z.Eskandani,J.M.Rassias,Approximately of a general cubic function equation in Felbin's fuzzy normed linear spaces[J],Results.Math.66,113-123(2014).

[9]C.Felbin,Finite dimensional fuzzy normed linear spaces[J],Fuzzy Set and Systems 48, 239-248(1992).

[10]J.Xiao,X.Zhu,Topological degree theory and fixed point theorems in fuzzy normed space[J].Fuzzy Sets Syst,147,437-452(2004). 